\title{
Refinement of two-dimensional electrophoresis for vitreous proteome profiling using an artificial neural network
}

\author{
Fátima M. Santos ${ }^{1,2,3,4}$ - Tânia Albuquerque ${ }^{1}$ - Leonor M. Gaspar ${ }^{1,2}$ • João M. L. Dias ${ }^{5}$ • João P. Castro e Sousa ${ }^{1,6}$. \\ Alberto Paradela ${ }^{7}$. Cândida T. Tomaz ${ }^{1,2} \cdot$ Luís A. Passarinha $^{1,4}(\mathbb{D}$
}

Received: 6 March 2019 / Revised: 18 April 2019 / Accepted: 30 April 2019 /Published online: 31 May 2019

(C) Springer-Verlag GmbH Germany, part of Springer Nature 2019

\begin{abstract}
Despite technological advances, two-dimensional electrophoresis (2DE) of biological fluids, such as vitreous, remains a major challenge. In this study, artificial neural network was applied to optimize the recovery of vitreous proteins and its detection by 2DE analysis through the combination of several solubilizing agents (CHAPS, Genapol, DTT, IPG buffer), temperature, and total voltage. The highest protein recovery $(94.9 \% \pm 4.5)$ was achieved using $4 \%(w / v)$ CHAPS, $0.1 \%(v / \mathrm{v})$ Genapol, $20 \mathrm{mM}$ DTT, and $2 \%(v / v)$ IPG buffer. Two iterations were required to achieve an optimized response (580 spots) using $4 \%(w / v)$ CHAPS, $0.2 \%(v / v)$ Genapol, $60 \mathrm{mM}$ DTT, and $0.5 \%(v / v)$ IPG buffer at $35 \mathrm{kVh}$ and $25^{\circ} \mathrm{C}$, representing a 2.4-fold improvement over the standard initial conditions of the experimental design. The analysis of depleted vitreous using the optimized protocol resulted in an additional 1.3-fold increment in protein detection over the optimal output, with an average of 761 spots detected in vitreous from different vitreoretinopathies. Our results clearly indicate the importance of combining the appropriate amount of solubilizing agents with a suitable control of the temperature and voltage to obtain high-quality gels. The high-throughput of this model provides an effective starting point for the optimization of 2DE protocols. This experimental design can be adapted to other types of matrices.
\end{abstract}

Keywords Artificial neural network · Gel-based proteomics · Ocular pathologies · Two-dimensional gel electrophoresis $\cdot$ Vitreous

$\begin{array}{ll}\text { Abbreviations } \\ \text { 2DE } & \text { Two-dimensional electrophoresis } \\ \text { ANN } & \text { Artificial neural networks } \\ \text { HMW } & \text { High-molecular-weight } \\ \text { IAA } & \text { Iodoacetamide }\end{array}$

\section{reviations}

ANN

IAA
IEF
$\mathrm{kVh}$
LMW Low-molecular-weight
MMW Medium-molecular-weight

Electronic supplementary material The online version of this article (https://doi.org/10.1007/s00216-019-01887-y) contains supplementary material, which is available to authorized users.

Luís A. Passarinha

lpassarinha@fcsaude.ubi.pt; lapp@ubi.pt

1 CICS-UBI - Health Sciences Research Centre, University of Beira Interior, 6201-506 Covilhã, Portugal

2 Chemistry Department, Faculty of Sciences, University of Beira Interior, 6201-001 Covilhã, Portugal

3 Laboratory of Pharmacology and Toxicology_UBIMedical, University of Beira Interior, 6200-284 Covilhã, Portugal
4 UCIBIO@REQUIMTE, Departamento de Química, Faculdade de Ciências e Tecnologia, Universidade Nova de Lisboa, 2829-516 Caparica, Portugal

5 Cancer Molecular Diagnostics Laboratory, National Institute for Health Research, Biomedical Research Centre, University of Cambridge, Cambridge, England, UK

6 Department of Ophthalmology, Centro Hospitalar de Leiria, 2410-197 Leiria, Portugal

7 Unidad de Proteomica, Centro Nacional de Biotecnología, CSIC, Calle Darwin 3, Campus de Cantoblanco, 28049 Madrid, Spain 


\section{Introduction}

Ocular proteomics has emerged as an opportunity for discovering new biomarkers, which could help to unveil the pathophysiology of many ocular diseases and anticipate its progression $[1,2]$. Vitreous is an ocular fluid localized between the inner retina and lens, and, as it is less complex than other ocular matrices, it could be an excellent source of biological material for the identification of subtle changes in protein expression $[2,3]$. As its proteome is affected by the physiological and pathological conditions of the retina, the study of vitreous has been a mean of indirectly understanding the vitreoretinal interface underlying many retinal diseases $[4$, 5]. Therefore, a comprehensive characterization of the vitreous proteome has been made to achieve this goal [6-19]. Gelfree techniques such as LC-MS and CE-MS have emerged as an alternative for the characterization of vitreous proteome [8-10, 19]; however, gel-based proteomic techniques are still widely used for in-depth proteome analyses [20,21].

Two-dimensional electrophoresis (2DE) combined with identification by MALDI-TOF/TOF mass spectrometry has been widely used for the analysis of vitreous proteome $[6,7$, 12-16]. If combined with more sensitive detection techniques, refined gel image processing, and proper sample preparation, $2 \mathrm{DE}$ is a valuable tool for routine and high-resolution analysis of proteoforms [22, 23]. Sample preparation has been the main focus in the optimization of 2DE protocols [24-26]. Protein extraction, enrichment, and solubilization should be adapted for each specific sample to improve the detection of protein diversity, removal of interfering substances, and interactions between polypeptides, without jeopardizing the yield and reproducibility [27, 28]. Moreover, the solubilizing agents must be compatible with isoelectric focusing (IEF) and preserve the protein solubilization at critical steps, e.g., at the sample entry into the gel and/or when protein achieves its isoelectric point [29]. Nevertheless, other strategies should be considered to avoid gel-to-gel variation, including the refinement and tuning of protein separation by isoelectric point (pI) [30-34] and by molecular weight (MW) $[33,35,36]$.

In this work, a careful combination of physicochemical factors that influence both sample preparation and separation by $\mathrm{pI}$ was considered for the analysis of vitreous proteins by $2 \mathrm{DE}$. In addition, an artificial neural network (ANN) was developed to maximize the number of protein spots detected in 2DE gels by combining different solubilizing agents (CHAPS, Genapol, DTT, IPG buffer) with the temperature and total voltage of IEF. Furthermore, ANN was used to improve protein recovery and solubilization from vitreous samples by combining the four solubilizing agents. By mimicking the structure and functional aspects of biological neural networks, ANN can be trained "by example" from a set of cases (inputs) to recognize patterns and to accurately predict responses (outputs) [37, 38].

\section{Materials and methods}

\section{Materials}

Solutions were prepared with ultrapure water obtained with a Milli-Q system (Millipore/Waters). Chemicals are commercially available and were used without further purification. 2DE QUANT kit, HiTrap ${ }^{\mathrm{TM}}$ Albumin \& IgG Depletion $1 \mathrm{~mL}$ column, immobilized $\mathrm{pH}$ gradient (IPG) strips, IPG buffer 3-10, iodoacetamide (IAA), and thiourea were obtained from GE Healthcare Life Sciences (Uppsala, Sweden). Genapol X-100, urea, alpha-cyano-4-hydroxycinnamic acid, bromophenol blue, Tris, ammonium bicarbonate, trypsin from porcine pancreas, and TFA were purchased from SigmaAldrich (St. Louis, MO, USA). DTT was obtained from Himedia (Mumbai, India). HPLC grade solvents (methanol and chloroform), LC-MS grade solvents (water and acetonitrile), glycerol, and Coomassie Brilliant Blue G-250 were acquired from Fluka Chemika (Buchs, Switzerland). CALMix was acquired from AB Sciex (Framingham, MA, USA). Acrylamide 4K solution 40\% was obtained from PanReac AppliChem (Darmstadt, Germany) and CHAPS was obtained from Amresco (OH, USA). Sodium phosphate, sodium chloride, and glycine were obtained from Fisher Scientific (Loughborough, UK).

\section{Patients and controls}

Vitreous samples were collected via pars plana vitrectomy, over a year period, at the Ophthalmology Service of Leiria-Pombal Hospital, Portugal. The protocol for sample collection was approved by the hospital ethics committee (Code: CHL-15481) and informed consent from all patients was obtained in agreement with the Declaration of Helsinki. Samples were collected from 16 patients with vitreomacular traction syndrome, of which 11 were diabetics and 5 non-diabetics. Patients included 4 females and 12 males, with ages comprised between 62 and 84 years. For the analysis of depleted samples, vitreous was collected from 3 individuals: a 68-year-old woman diagnosed with proliferative diabetic retinopathy, a 70-year-old man diagnosed with rhegmatogenous retinal detachment, and a 65-yearold woman with cortical fragments. Vitreous samples were transferred to sterile cryogenic vials after collection and frozen at $-80{ }^{\circ} \mathrm{C}$ until further processing.

\section{Experimental design}

A set of 30 exploratory experiments were designed using the Screening option in MODDE 12.1 based on a factorial design at three levels (L27) with three central points. Six factors that influence the extraction, solubilization, and separation by IEF of vitreous proteins were considered for maximizing the detection of spots in 2DE gels, including solubilizing agents and 
physical parameters. The solubilizing agents comprised detergents (CHAPS at 0,2 , and $4 \%(w / v)$ and/or Genapol at $0,0.1$, and $0.2 \%(v / v))$, DTT $(20,40$, and $60 \mathrm{mM})$, and IPG buffer $(0.5$, 1 , and $2 \%(v / v))$. The physical parameters were the total voltage $(35,40$, and 45 kilovolts hour $(\mathrm{kVh}))$ and temperature $(15,20$, and $25^{\circ} \mathrm{C}$ ). Table S1 (see Electronic Supplementary Material, ESM) lists the physical-chemical parameters and respective ranges combined for the experimental design, the model development, and the optimization by ANN.

\section{Extraction and solubilization of vitreous proteins}

Individual vitreous samples were centrifuged at $18,620 \times g$ for $10 \mathrm{~min}$ at $4{ }^{\circ} \mathrm{C}$, and the resultant supernatants from 16 patients were pooled for further analysis. The pool was quantified using 2DE Quant kit (GE Healthcare Life Sciences). Proteins were extracted from vitreous using chloroform/ methanol precipitation, as previously described $[10,18]$. Briefly, $800 \mu \mathrm{L}$ methanol, $200 \mu \mathrm{l}$ chloroform, and $600 \mu \mathrm{L}$ Milli-Q water were added to $200 \mu \mathrm{L}$ of sample. The mixture was centrifuged at $15,000 \times \mathrm{g}$ for $5 \mathrm{~min}$ at $4{ }^{\circ} \mathrm{C}$, and the aqueous layer was removed. After centrifugation, $800 \mu \mathrm{L}$ of methanol was added, and the protein pellet was recovered after centrifugation at $18,620 \times \mathrm{g}$ for $10 \mathrm{~min}$. The pellet was solubilized with a buffer composed of $7 \mathrm{M}$ urea, $2 \mathrm{M}$ thiourea, and $0.002 \%(w / v)$ bromophenol blue and supplemented with CHAPS, Genapol, DTT, and IPG buffer, according to the experimental design (ESM Table S1). All samples were prepared at least in triplicate for each run.

\section{Two-dimensional gel electrophoresis}

IPG strips (pH 3-10, $24 \mathrm{~cm}$ ) were rehydrated, according to experimental design, for $14 \mathrm{~h}$ at room temperature. According to optimized conditions, $250 \mu \mathrm{g}$ of vitreous proteins was applied by cup loading and separated by isoelectric focusing in an Ettan IPGphor III device (GE Healthcare Life Sciences) for a total of 35,40 , or $45 \mathrm{kVh}$, with temperatures ranging between 15,20 , and $25^{\circ} \mathrm{C}$ (ESM Table S2). Technical duplicates were performed for each experiment. IPG strips were incubated for $15 \mathrm{~min}$ with equilibration buffer (6 M urea, $75 \mathrm{mM}$ Tris- $\mathrm{HCl}$ buffer, $29.3 \%(v)$ v) glycerol, $2 \%(w / v)$ SDS, $0.02 \%(w / v)$ bromophenol blue) supplemented with $1 \%(w / v)$ DTT, and, subsequently, for $15 \mathrm{~min}$ with equilibration buffer supplemented with $2.5 \%(w / v)$ IAA. The second dimension was performed on $10 \%$ acrylamide gels, using Ettan DALTSIX Large Vertical System (GE Healthcare Life Sciences, Sweden). Gels were initially run at $1.5 \mathrm{~mA} / \mathrm{gel}$ for $45 \mathrm{~min}$ and, then, at $17 \mathrm{~mA} /$ gel to separate the proteins by MW. Gels were stained using a colloidal Coomassie Brilliant Blue solution [18, 39] and scanned using ImageScanner III (GE Healthcare Life Sciences, Sweden). The spots were automatically detected using the ImageMaster 2D Platinum v7.0 (GE Healthcare) software. The detection was performed using the following parameters, smooth $=3$, minimum area $=5$, and saliency $=15$, and artifacts (e.g., dust, bubbles, among others) and edges of the images were manually removed. The total number of proteins spots, volume, intensity, and saliency was assessed for each experiment.

\section{Artificial neural network}

A feed-forward ANN was applied to predict the number of protein spots detected in 2DE gels as a function of the solubilizing conditions (CHAPS, Genapol, DTT, IPG buffer), total voltage, and temperature. The ANN tool was implemented in MATLAB $^{\mathrm{TM}}$ using the Neural Network Toolbox and the "newff" function. The ANN structure, comprising a total of 17 parameters, was designed with an input layer with six neurons (one for each input variables), an output layer with one neuron (number of detected spots), and one hidden layer with two neurons $(6 / 2 / 1)$. The transfer functions for the input and output layers were defined by the linear function "purelin" and for the hidden layer by the log-sigmoid function "logsig." The ANN model training was performed with LevenbergMarquardt back-propagation method "trainlm," up to 1000 epochs, using the "train" function with the performance function "mse" goal set at $1 \times 10^{-10}$. The remaining training parameters were set at their default values. The parameter optimization for each model was carried out until either the maximum number of epochs or the performance goal was reached. A randomly selected dataset, containing $25 \%$ of the total number of experiments, was left aside for model validation. The outliers were discarded from the dataset using the modified Thompson Tau test for a Student's $t$ critical value (based on an alpha level of 0.075 ) with two degrees of freedom. The model selection process was repeated until the coefficient of determination $\left(R^{2}\right)$ for the selected set (excluding the outliers) of observed versus the predicted number of protein spots has exceeded 0.925 . The optimized ANN inner parameters are present in ESM Table S2.

\section{Analysis of depleted vitreous using 2DE optimal operation conditions}

Human serum albumin and IgG were depleted from individual vitreous samples using a HiTrap ${ }^{\mathrm{TM}}$ Albumin \& IgG Depletion $1 \mathrm{~mL}$ column (GE Healthcare, Uppsala, Sweden), as previously performed by our group [18]. The depletion was performed at room temperature in an ÄKTA avant FPLC system with UNICORN software (GE Healthcare, Uppsala, Sweden) equipped with a 1-mL injection loop. All buffers were prepared with Milli-Q system water, filtered through a $0.20-\mu \mathrm{m}$ pore size membrane (Schleicher Schuell, Dassel, Germany) and degassed ultrasonically. The flow-through fraction containing lowabundant non-bound proteins was collected, desalted using Vivaspin 6, $3 \mathrm{kDa}$ MWCO (GE Healthcare), and precipitated as described before. The pellet obtained was solubilized in a 
buffer composed of $7 \mathrm{M}$ urea, $2 \mathrm{M}$ thiourea, 4\% (w/v) CHAPS, $0.1 \%(v / v)$ Genapol, $20 \mathrm{mM}$ DTT, and 2\% (v/v) IPG buffer. IEF was performed with an IPG strip rehydrated with $7 \mathrm{M}$ urea, $2 \mathrm{M}$ thiourea, 4\% (w/v) CHAPS, 0.2\% (v/v) Genapol, $60 \mathrm{mM}$ DTT, and $0.5 \%(v / v)$ IPG buffer. A total of $250 \mu \mathrm{g}$ was focused at $35 \mathrm{kVh}$ and $25^{\circ} \mathrm{C}$, as previously performed.

\section{Protein identification}

Protein spots were manually excised from 2DE gels, destained $(50 \%(v / v)$ acetonitrile in $50 \mathrm{mM}$ ammonium bicarbonate), reduced $\left(10 \mathrm{mM}\right.$ DTT, $1 \mathrm{~h}$ at $\left.37^{\circ} \mathrm{C}\right)$, and alkylated $(55 \mathrm{mM}$ IAA, $30 \mathrm{~min}$ at room temperature). Then, spots were rehydrated for $1 \mathrm{~h}$ with $30 \mu \mathrm{L}$ of $10 \mathrm{ng} / \mu \mathrm{L}$ of trypsin solution at $4{ }^{\circ} \mathrm{C}$ and digested overnight at $37^{\circ} \mathrm{C}$. Tryptic peptides were extracted and salts washed with Zip-tip pipette tips C18 0.1$10 \mu \mathrm{L}$ pipette tips (Millipore $\AA$, Molsheim, France), as previously described [18]. MS and MS/MS spectra were acquired on a 4800 plus MALDI-TOF/TOF mass analyzer (AB Sciex, Framingham, MA, USA), equipped with a 355-nm laser. MALDI-TOF/TOF was initially calibrated, using the CALMix 1/CALMix 2 calibration mixture that includes the following components: des-arg-bradykinin $(904.4681 \mathrm{~m} / \mathrm{z}$ ), angiotensin I $(1296.6853 \mathrm{~m} / \mathrm{z})$, Glu-fibrinopeptide B $(1570.6774 \mathrm{~m} / \mathrm{z})$, and ACTH $(2093.0867 \mathrm{~m} / \mathrm{z})$. Tryptic peptides corresponding to individual spots were mixed with $5 \mathrm{mg} /$ $\mathrm{mL}$ of alpha-cyano-4-hydroxycinnamic acid in proportion 1:1 and spotted on a MALDI plate. All spots were acquired in positive MS reflector mode in the range 800 to $4000 \mathrm{~m} / \mathrm{z}$ by averaging 1500 laser spots. The eight more intense MS ions per spot that satisfied the precursor criteria (200 ppm fractionto-fraction precursor exclusion, $S / N$ ratio $>25$ ) were selected for subsequent MS/MS analysis. MS/MS analysis was performed using $1 \mathrm{keV}$ collision energy of $1 \mathrm{kV}$ with a total of 1500 laser shots per spectrum. Raw data were searched using the MASCOT search engine from ProteinPilot ${ }^{\mathrm{TM}}$ Software 4.5 (AB Sciex, Framingham, MA, USA) against the Homo sapiens UniProtKB reviewed database (20,360 entries, 9th of July 2018). Search parameters were set as follows: enzyme - trypsin, fixed modifications - carboxymethyl (C), variable modifications - oxidation $(\mathrm{M})$, peptide mass tolerance \pm 100 ppm, fragment mass tolerance \pm 0.3 Da, missed cleavages 2. Protein scores of 56 were used as a cutoff for protein identification using MASCOT $(p<0.05)$.

\section{Results}

\section{Experimental design and artificial neural network modeling}

For the design of the ANN, both solubilizing agents and physical parameters were selected as inputs variables. The inputs variables and respective range levels were selected according to previous studies in the literature $[3,6,12-14,16]$ and to preliminary results from our research group. According to the literature, CHAPS $(0,2$, and 4\% (w/v)), DTT (20, 40, and $60 \mathrm{mM})$, and IPG buffer $(0.5,1$, and $2 \%(v / v))$ were selected as inputs. Additionally, the non-ionic detergent Genapol (0, 0.1, and $0.2 \%(v / v))$ was included in this study because of its good performance in protein recovery from vitreous samples [40]. Chaotropic agents were not selected as inputs, but $7 \mathrm{M}$ urea/ $2 \mathrm{M}$ thiourea were included in all the buffers used for extraction and solubilization of vitreous proteins. Temperatures between 15 and $25{ }^{\circ} \mathrm{C}$ were tested, according to the results obtained by Görg and colleagues [41]. Total voltage was 35 to $45 \mathrm{kVh}$ for $24 \mathrm{~cm}$ IPG strips pH 3-10, according to the manufacturer. According to this, the inputs variables and respective code levels were defined for the experimental design, as shown in ESM Table S1. The 30 experiments defined by CCD for the optimization of the number of proteins spots detected in the 2DE analysis are listed in ESM Table S2.

\section{Improvement of protein extraction based on the ANN model}

The first goal of this study was to establish a cost-effective protocol for the extraction and solubilization of vitreous proteins for 2DE analysis. Preliminary results showed that acetone precipitation leads to an unreproducible recovery of proteins from vitreous, with poor recovery yields $(59 \% \pm 27)$. TCA/acetone precipitation was remarkably more efficient than acetone alone, with recovery yields of $84 \% \pm 18$, similar to the results (>90\%) obtained with 2-D Clean-Up Kit (GE Healthcare). Nevertheless, the cost makes inconceivable its use for the preparation of many samples. The choice turned out to be a methanol/chloroform precipitation due to its easy and fast handling, efficiency, and cost-effectiveness. The effect of the four solubilizing components (CHAPS, Genapol, DTT, IPG buffer) on the protein solubilization was studied using the ANN experimental design (ESM Table S1). Table 1 shows the recovery yields obtained in the solubilization of vitreous proteins combining distinct solubilizing agents, with values ranging between $72.7 \% \pm 5.4$ and $94.9 \%$ \pm 4.5 . We found that CHAPS showed the greatest improvement on protein solubilization, with recovery yield increases from 78.2 to $87.2 \%$ by varying its concentration from 0 to $4 \%$ $(w / v)$. The effect of Genapol on the protein solubilization was more evident at low percentages of CHAPS. Therefore, such high concentrations of Genapol are not required in the presence of CHAPS. IPG buffer did not have a relevant impact on recovery yields, but best results were obtained at $2 \%(v / v)$. Lower concentrations of DTT (20-40 mM) increased protein recovery. Combining all factors, the highest protein recovery $(94.9 \% \pm 4.5)$ was achieved combining $4 \%(w / v)$ CHAPS, $0.1 \%(v / v)$ Genapol, $20 \mathrm{mM}$ DTT, and 2\% (v/v) IPG buffer. 
Table 1 Recovery yields obtained in the solubilization of vitreous proteins with different combinations of solubilizing agents

\begin{tabular}{|c|c|c|c|c|c|}
\hline \multirow{2}{*}{$\begin{array}{l}\text { Experiment } \\
\text { number }\end{array}$} & \multicolumn{4}{|c|}{ Solubilizing agents } & \multirow{2}{*}{$\begin{array}{l}\text { Output } \\
\text { Protein recovery per } \\
\text { buffer }(\%)\end{array}$} \\
\hline & $\begin{array}{l}\text { CHAPS }(\% \\
w / v)\end{array}$ & $\begin{array}{l}\text { Genapol }(\% \\
v / v)\end{array}$ & $\begin{array}{l}\text { DTT } \\
(\mathrm{mM})\end{array}$ & $\begin{array}{l}\text { IPG buffer }(\% \\
v / v)\end{array}$ & \\
\hline $1,2,3$ & 0 & 0.0 & 20 & 0.5 & $80.1 \pm 5.9$ \\
\hline $4,5,6$ & 0 & 0.1 & 40 & 1.0 & $81.9 \pm 14.3$ \\
\hline $7,8,9$ & 0 & 0.2 & 60 & 2.0 & $72.7 \pm 5.4$ \\
\hline $10,11,12$ & 2 & 0.0 & 40 & 2.0 & $90.0 \pm 5.3$ \\
\hline $13,14,15$ & 2 & 0.1 & 60 & 0.5 & $87.1 \pm 4.8$ \\
\hline $16,17,28$ & 2 & 0.2 & 20 & 1.0 & $81.7 \pm 7.0$ \\
\hline $19,20,21$ & 4 & 0.0 & 60 & 1.0 & $84.5 \pm 10.0$ \\
\hline $22,23,24$ & 4 & 0.1 & 20 & 2.0 & $94.9 \pm 4.5$ \\
\hline $25,26,27$ & 4 & 0.2 & 40 & 0.5 & $86.3 \pm 5.4$ \\
\hline $28,29,30$ & 2 & 0.1 & 40 & 1.0 & $84.4 \pm 11.7$ \\
\hline 31,32 & 4 & 0.2 & 60 & 0.5 & $83.2 \pm 12.0$ \\
\hline
\end{tabular}

\section{Modeling of the number of spots detected in 2DE analysis using an ANN model}

Experimental conditions for vitreous proteome profiling by 2DE were optimized by ANN modeling using a stepwise process to maximize the number of detected protein spots. The ANN model is slightly biased with a slope and intercept of 0.91 and 20.49, respectively, and an $R^{2}$ of the fitting between the measured and predicted output of 0.925 (Fig. 1a). Two iterations were required to achieve an optimal response (580 spots) under the optimal conditions (4\% ( $w / v)$ CHAPS, $0.2 \%$ $(v / v)$ Genapol, $60 \mathrm{mM}$ DTT, $0.5 \%(v / v)$ IPG buffer at $35 \mathrm{kVh}$ and $25^{\circ} \mathrm{C}$ ). Figure $1 \mathrm{~b}$ depicts the contour plots from the ANN model for the two-factor interaction between the solubilizing agents (CHAPS, Genapol, DTT, and IPG buffer) and the physical parameters (temperature and total voltage), respectively. The optimal run (experiment 32) showed a $20.6 \%$ (1.2-fold) and $134.7 \%$ (2.4-fold) improvement over the best (experiment 25 ) and the more standard (experiment 21) conditions performed in the experimental design. The two-factor interaction between Genapol and CHAPS (Fig. 1b) evidences an abrupt reduction in the response (less than 200 spots) when lower concentrations of detergents are applied. Percentages of Genapol above $0.15 \%(v / v)$ promote a positive outcome, which is reinforced in the presence of CHAPS. Genapol has a positive effect on the spot detection, even without CHAPS, but the opposite situation is not verified. In fact, less than 200 spots are detected without Genapol, even at higher concentrations of CHAPS. Higher outcomes are also accomplished with $60 \mathrm{mM}$ DTT and $0.5 \%(v / v)$ IPG buffer (Fig. 1b). Good responses are obtained combining $20 \mathrm{mM}$ of DTT and $0.15 \%(\mathrm{v} /$ v) Genapol but, as the detergent concentration rises, increasing the DTT concentration is also required. According to that, the best results were obtained in experiments 25 and 32 using
$0.5 \%(v / v)$ IPG buffer, in which 514 and 584 spots were detected in 2DE gels.

Concerning the physical parameters, optimal results are obtained with high temperatures $\left(25^{\circ} \mathrm{C}\right)$ and lower total voltages $(35 \mathrm{kVh})$ (Fig. 1b). The effect of physical parameters in protein detection appears to be highly influenced by the levels of Genapol and DTT but not by the concentration of CHAPS and IPG buffer (Fig. 1b). As Genapol percentage increases, higher temperatures and lower voltages are required to maintain an effective detection level. Indeed, temperature, voltage, and DTT should be carefully maintained close to the optimal values to obtain the best outcome. Also, the set voltage was not reached in some experiences, especially in those that combined higher concentrations of DTT and/or IPG buffer with higher voltages.

\section{Effect of ANN factors in the quality of 2DE gels}

After validation, the gels were visually inspected, and several protein spots were manually excised and identified by mass spectrometry to confirm the robustness of the established ANN model. Furthermore, parameters such as intensity, area, saliency, and volume of the spots were measured in gel images using the ImageMaster 2D Platinum v7.0 software (ESM Table S2). Visual inspection of gels with increasing concentrations of detergents allowed us to detect changes in spot patterns throughout the experimental optimization. Figure 2 shows the contour plot of two-factor interaction between CHAPS and Genapol and the representative 2DE gels obtained at different conditions (experiments 2 (a), 7 (b), 13 (b), 21 (e), and 25 (d) from ESM Table S2). The spots identified by MALDI-TOF/ TOF are shown in detail in the 2DE gel from experiment 32 (Fig. 3a) and the complete list of identified proteins and peptides are listed in ESM Table S3. The 3D visualization of highMW (HMW), medium-MW (MMW), and low-MW (LMW) 
a

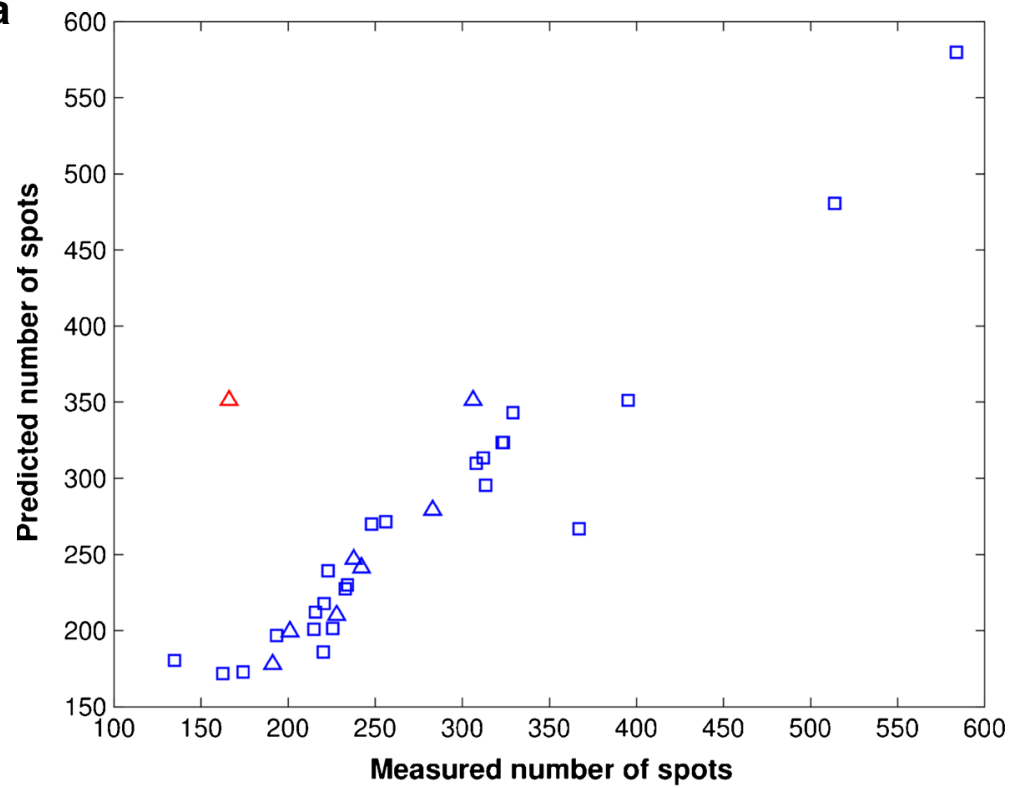

b
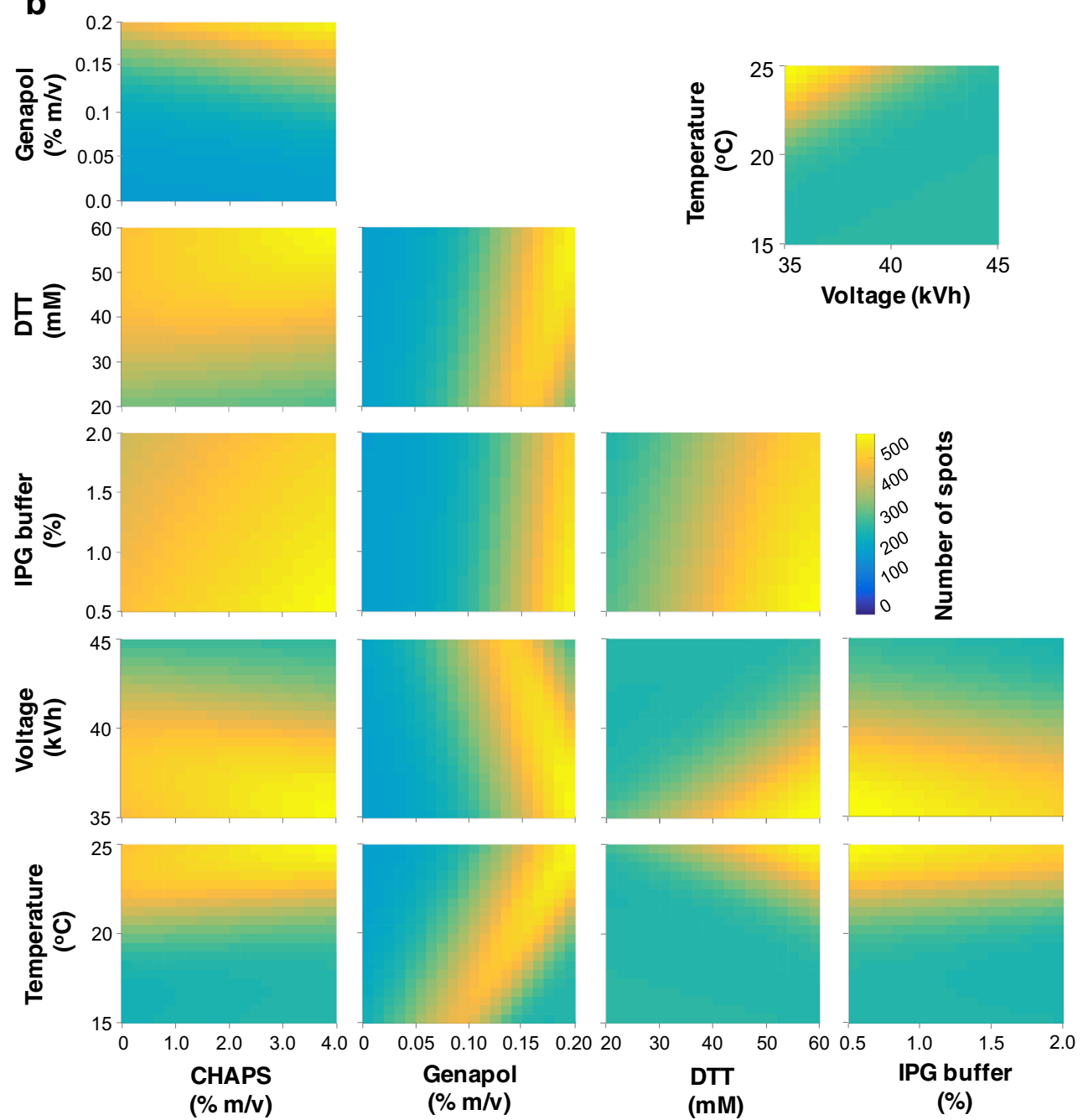

(\%) 
Fig. 1 (a) Artificial neural network model fitting comparing the experimental and predicted number of spots detected in twodimensional gels. The experiments used for the training (squares) and the validation (triangles) of the experimental design are represented in blue and the outliers (experiment 30) in red. (b) Contour plots obtained from the ANN model for the two-factor interaction between solubilizing agents and physical parameters (temperature and total voltage)

areas from representative $2 \mathrm{DE}$ gels obtained throughout the experimental optimization is shown in Fig. 3 b.

In gels with the highest number of spots (e.g., experiment 25 in Fig. 2d), the volume/area occupied by high-abundant protein spots is lower, compared with the gels with fewer spots (e.g., experiment 2 in Fig. 2a). A close look at highly abundant vitreous proteins such as alpha-1-antitrypsin, serotransferrin, and albumin (spots 5, 6, and 7 in Fig. 3a) showed a significant increase in intensity/saliency with the improvement of experimental conditions, but a decrease in the percentage of occupied volume. The number of proteins ranging between 48 and $75 \mathrm{kDa}$ did not increase so significantly through the optimization, but this increase was significant for high- and lowmolecular-weight proteins. Up to $81 \mathrm{HMW}$ and $42 \mathrm{LMW}$ proteins were found in gels with lower number spots (e.g., experiments 2, 7, and 13), but 173 high- and 69 low-mass proteins were detected using optimal conditions (ESM Table S2). As shown in Figs. 2 and 3, it is evident the positive effect of Genapol on the detection of these proteins. For example, HMW proteins, such as retinol-binding protein (spot 1) and ceruloplasmin (spots 2), or LMW proteins, such as immunoglobulin light chains (spots 14 and 15), were barely visible in the first experiments but showed a substantial increase in its intensity/saliency through the optimization process (ESM Table S2). Spot resolution was also increased, particularly in experiments using 40-60 $\mathrm{mM}$ of DTT (Fig. 3b). DTT led to a more significant increase in protein detection in ranges between 35 and $75 \mathrm{kDa}$ than at HMW and LMW ranges (ESM Table S2). Furthermore, it was verified that spot resolution is negatively affected by lower temperatures and high voltages. At these conditions, the gels present distorted protein patterns with poorly resolved spots and an extensive horizontal and vertical streaking. These effects are attenuated by the presence of Genapol and/or DTT, as seen in experiments 7 (Fig. 2b), 18, and 20 .

\section{Analysis of depleted vitreous using 2DE optimal operation conditions}

Despite the improvement of the experimental conditions, an extensive vertical and horizontal streaking pattern is visible in the gels run on undepleted samples. To improve the quality of

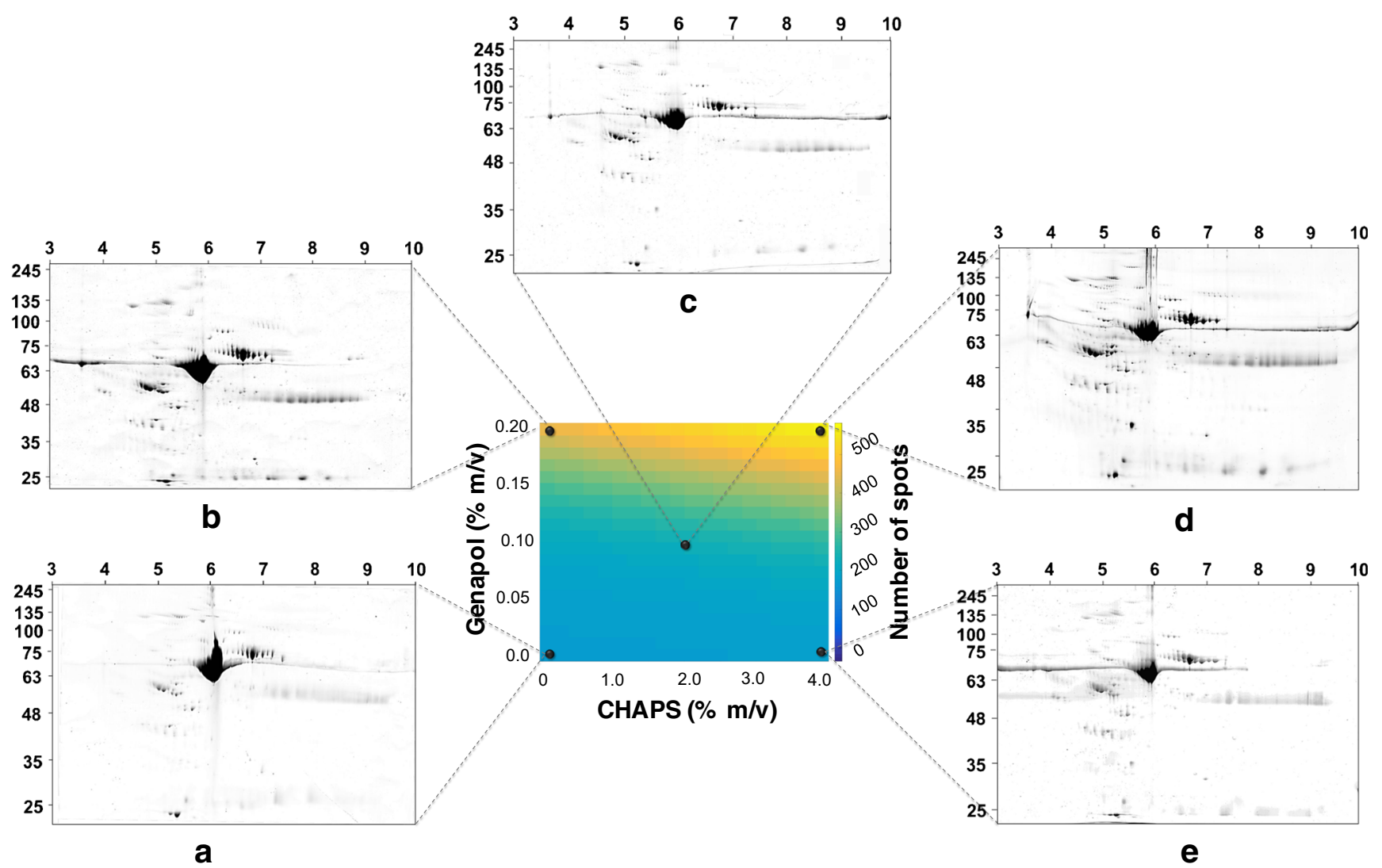

Fig. 2 Contour plot of two-factor interaction between the detergents CHAPS and Genapol and the representative 2DE gels for the experiments (a) 2, (b) 7, (c) 13, (d) 25, and (e) 21. The concentration of CHAPS and Genapol used in each experiment is represented in the contour plot by black spots 
$10 \mathrm{pH}$

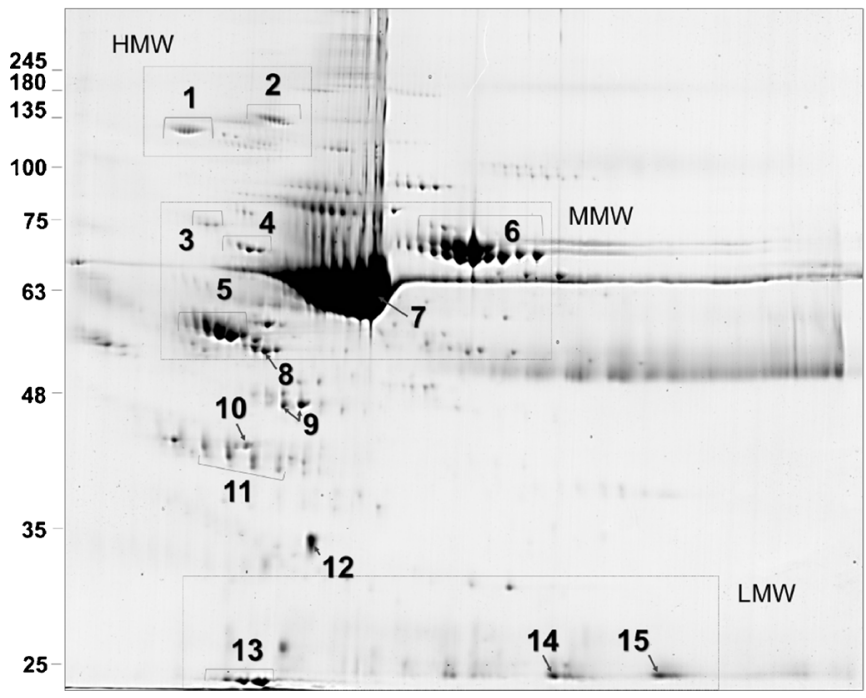

a

Fig. 3 (a) Representative 2DE gels from the analysis of vitreous in experiments 32 using 4\% (w/v) CHAPS, $0.2 \%(v / v)$ Genapol, $60 \mathrm{mM}$ DTT, and $0.5 \%(v / v)$ IPG buffer at $35 \mathrm{kVh}$ and $25{ }^{\circ} \mathrm{C}$. The numbered spots were identified was 1: retinol-binding protein 3, 2: ceruloplasmin, 3 : prothrombin, 4: alpha-1B-glycoprotein, 5: alpha-1-antitrypsin, 6: serotransferrin, 7: serum albumin, 8: vitamin D-binding protein, 9:

gels, albumin and $\operatorname{IgG}$ were removed using HiTrap ${ }^{\mathrm{TM}}$ Albumin \& IgG Depletion $1 \mathrm{~mL}$ column and depleted vitreous samples were analyzed by 2DE using the optimized protocol. For this purpose, vitreous was collected from three different samples, including a woman with cortical fragments in vitreous (HV 24), a woman diagnosed with PDR (HV 26), and a man diagnosed with rhegmatogenous retinal detachment (HV 580). Depletion of high-abundant proteins resulted in a substantial increase in the number of protein spots detected in the gels, with 798, 701, and 785 spots detected in HV 24, HV 580, and HV 26, respectively (Fig. 4a-c). On average, this represents an increase of $23.1 \%$ (1.3-fold) in global protein detection over the optimal output of the ANN model. Overlap analysis of the 2DE gels from experiment 32 (blue) and depleted vitreous (red) 24 indicated new spots (black) detected in regions previously occupied by albumin and IgG (Fig. 4d). At these conditions, it was possible to identify 445 spots in MMW region, compared with the 353 spots previously detected in experiment 32. Also, more 42 LMW proteins and 33 HMW proteins were detected, and other spots become more visible in the gels after albumin and IgG removal.

\section{Discussion}

2DE remains a valuable tool for the high-resolution analysis of vitreous proteome $[6,7,12-16]$ due to its affordable price,
HMW
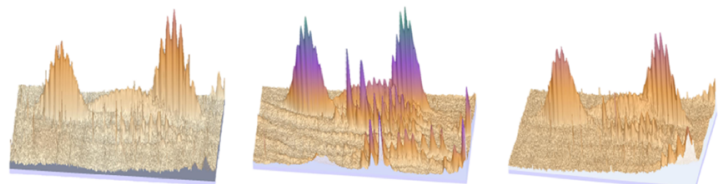

MMW
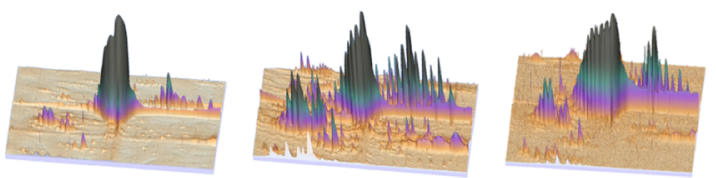

LMW
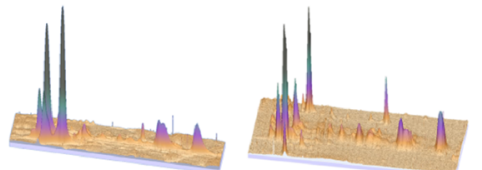

$0 \%$ CHAPS,

$0.2 \%$ Genapol $40 \mathrm{mM}$ DTT,

$0.5 \%$ IPG buffer

$35 \mathrm{kVh}$

$25{ }^{\circ} \mathrm{C}$

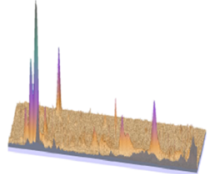

$0 \%$ CHAPS,

$0.2 \%$ Genapol $0.5 \%$ IPG buffer $35 \mathrm{kVh}$ $25^{\circ} \mathrm{C}$ $60 \mathrm{mM}$ DTT,

\section{b}

pigment epithelium-derived factor, 10: apolipoprotein A-IV, 11: haptoglobin, 12: transthyretin, 13: apolipoprotein A-I, 14: immunoglobulin kappa constant, 15: immunoglobulin kappa light chain. (b) 3D visualization of high-molecular-weight (HMW), medium-molecular-weight (MMW), and low-molecular-weight (LMW) regions of 2DE gels obtained throughout the experimental optimization

robustness, and high-resolution. Nevertheless, both proteome complexity and wide dynamic range of vitreous samples hinder its analysis by 2DE. The present work aimed to establish a cost-effective experimental protocol for the analysis of vitreous by $2 \mathrm{DE}$ considering some parameters with potential impact on its solubilization, extraction, and detection. In the first approach, the extraction method was selected using the traditional one-factor-at-a-time approach. Although this methodology is useful for a preliminary screening, it is extremely timeconsuming and it is not efficient to evaluate in an objective manner the interaction between inputs in multifactorial systems [42-44]. Considering the substantial number of factors under study, multivariate statistical methodologies were applied to evaluate the effect of multiple factors in the final response. Response surface methodology (RSM), which includes factorial design and regression analysis, is useful to optimize significant factors to maximize the response [43], but this model would have 28 parameters compared with 17 parameters of our ANN model. According to that, a set of 30 exploratory experiments were designed based on a factorial design at three levels (L27) with three central points. ANN was used to explore the effect of the combination of six factors that influence vitreous protein analysis by $2 \mathrm{DE}$, including solubilizing agents (CHAPS, Genapol, DTT, IPG buffer) and physical parameters (total voltage and temperature). We found that optimal conditions (run 32) included 4\% (w/v) CHAPS, $0.2 \%(v / v)$ Genapol, $60 \mathrm{mM}$ DTT, and $0.5 \%(v / v)$ IPG buffer 
3

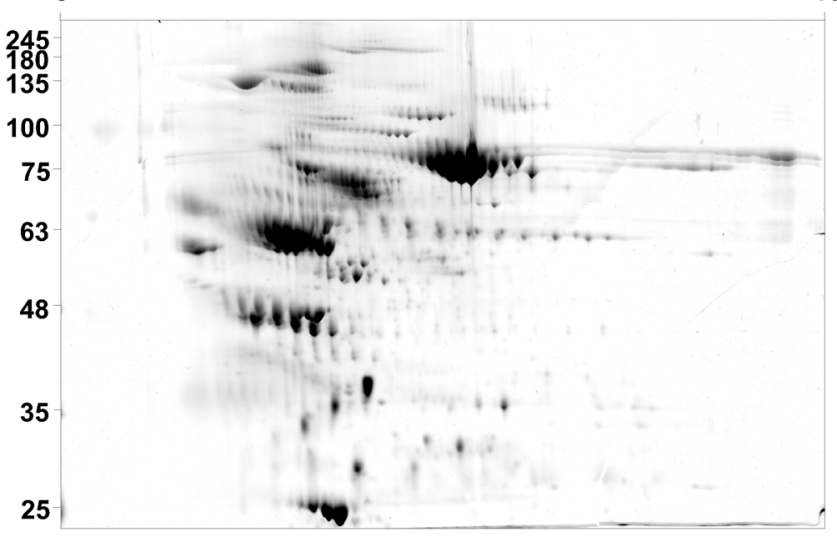

a

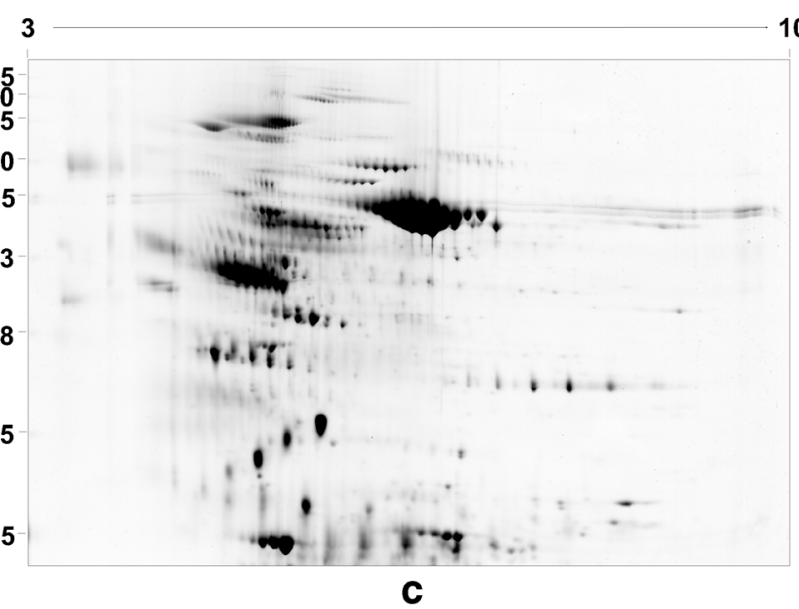

Fig. 4 Representative 2DE gels from the analysis of depleted vitreous collected from (a) a patient diagnosed with PDR (HV 26), (b) a patient diagnosed with rhegmatogenous retinal detachment (HV 580), and (c) a patient with cortical fragments in vitreous (HV 24). (d) Image

at $35 \mathrm{kVh}$. These conditions allowed us to detect 580 spots, representing a 1.2-fold/2.4-fold improvement over the best/ standard conditions performed in the experimental design. For maximizing the protein recovery yield $(94.9 \% \pm 4.5)$, the conditions were similar, but it was preferable to decrease the concentration of DTT to $20 \mathrm{mM}$ and of Genapol to $0.1 \%(v / v)$.

CHAPS is the most commonly used surfactant in $2 \mathrm{DE}$ protocols due to its greater solubilizing power [45]. In this work, CHAPS allowed recoveries greater than $80 \%$ and promoted the detection of more than 200 spots. Although the performance of CHAPS was reasonable, it has been reported that it is worst for the extraction of challenging proteins (e.g., hydrophobic and/or HMW proteins) [29]. To increase its solubilizing power, the buffer was complemented with Genapol, a non-ionic detergent that demonstrated high efficiency for the extraction of vitreous proteins [40]. In fact, Genapol has a positive effect on the detection of protein spots, even in the absence of CHAPS. DTT showed superior performance at increasing concentrations, which can be related to its potential
10

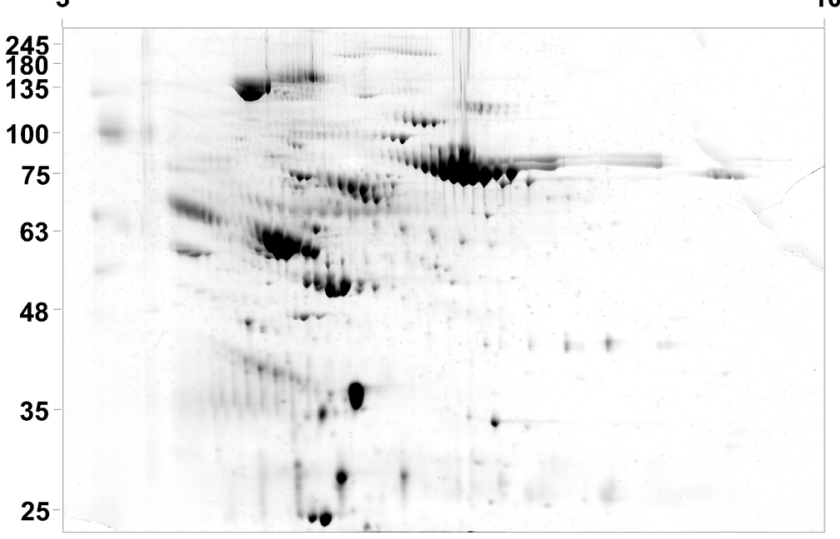

b

3

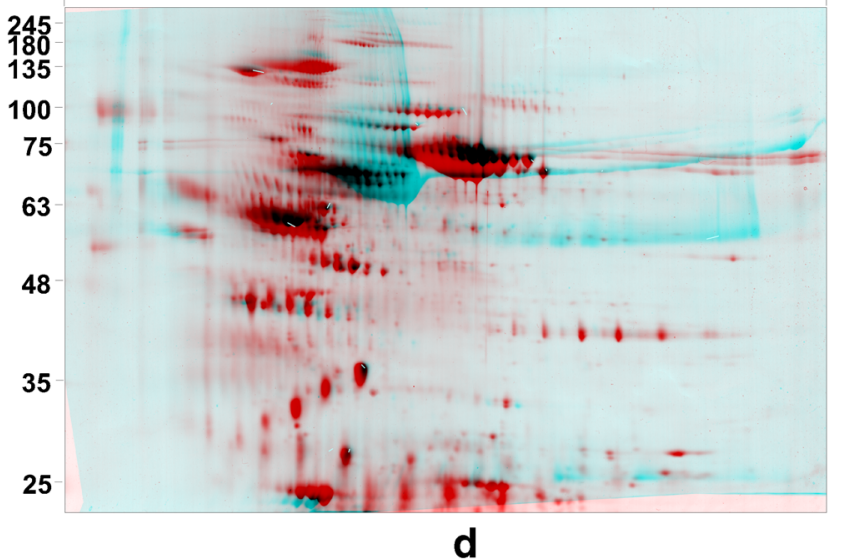

representing the overlapping of representative $2 \mathrm{DE}$ gels from the analysis of depleted vitreous HV 24 (colored at red) and the 2DE gels from the analysis of vitreous in experiments 32 (colored at blue). The black spots correspond to overlapping spots between the two gels

interference with IEF. DTT becomes deprotonated as it moves towards the anode, which increases the conductivity in IEF and diminishes the reducing power at the cathode region. At these conditions, proteins become less soluble and tend to precipitate, causing horizontal streaking and poor resolution in the second dimension of 2DE [46]. Best results were obtained with $60 \mathrm{mM}$ DTT combined with reduced voltages $(35 \mathrm{kVh})$ to avoid potential interferences in long runs. Besides, the combination of high concentration of DTT/IPG buffer with lower temperatures/high voltages results in poor focusing of vitreous proteins. At these conditions, the gels present distorted protein patterns with poorly resolved spots and an extensive horizontal and vertical streaking. Temperature is a critical parameter since it largely affects $\mathrm{pI}$ values, with variations up to $0.6 \mathrm{pH}$ units between 4 and $25^{\circ} \mathrm{C}$ $[28,41]$. Although the temperature of $20^{\circ} \mathrm{C}$ is the most recommended for IEF, our results indicate that a slight increase to $25^{\circ} \mathrm{C}$ can benefit the quality of vitreous analysis by $2 \mathrm{DE}$. As previously reported by Görg and co-workers, the entry and 
mobility of proteins in IPG strips are improved with a slighter increase in the temperature, and, consequently, clearer background gels with well-defined spots are obtained [41]. Considering that, it must be kept in mind that physical parameters such as temperature and voltage have an enormous impact on the final quality of gels and, thus, should be recorded and controlled during the IEF.

Despite the meticulous refinement of several parameters, high-abundant proteins, such as albumin, cause an extensive vertical and the horizontal streaking, which hampers the detection of less abundant proteins. The complexity and wide dynamic concentration range of biological fluids exceed the high resolving power of $2 \mathrm{DE}$, and, therefore, it is highly recommended to reduce the complexity of the sample previously to $2 \mathrm{DE}$ analysis $[3,20]$. In this study, the depletion of abundant proteins including albumin and IgG allowed an increase of $23.1 \%$ (1.3-fold) in the number of proteins detected over the optimal conditions performed without depletion. Although the depletion of abundant proteins can lead to the co-depletion of important proteins, it seems to be a suitable approach to increase the coverage of vitreous proteome.

\section{Conclusions}

Despite technological advances, the 2DE analysis of biological fluids, such as vitreous, remains a major challenge. In this work, an ANN was developed to maximize the extraction of vitreous proteins and its detection in 2DE gels by combining solubilizing agents (CHAPS, Genapol, DTT, and IPG buffer) at different temperatures and total voltages. The best protein recovery was obtained using 4\% (w/v) CHAPS, 0.1\% (v/v) Genapol, $20 \mathrm{mM}$ of DTT, and 2\% (v/v) IPG buffer, with recoveries of $94.9 \% \pm 4.5$, but it was required to increase the DTT and Genapol concentration and to decrease the percentage of IPG buffer to maximize the protein detection in gels. In these conditions, 580 spots were detected in 2DE gels, showing a 2.4-fold improvement over the standard conditions of the experimental design. Our results clearly indicate that it is crucial to combine appropriate amounts of chaotropes, detergents, ampholytes, and reducing reagents to improve protein extraction and detection and to obtain well-resolved gels. Beyond the complexity of maintaining protein solubility in IEF, it must be kept in mind that physical parameters have a relevant role and should be recorded and controlled during the experimental procedure. Finally, when working with biological fluids, it is important to reduce sample complexity before $2 \mathrm{DE}$ analysis to facilitate the access to the low-abundant proteins, and to increase the proteome coverage. Besides obtaining optimal conditions for the extraction and analysis of vitreous proteins by $2 \mathrm{DE}$, the ANN is helpful to understand how different parameters can affect the visual aspect of gels and resolution of protein spots. This experimental design and model can be adapted to other types of samples, depending on the characteristics of proteins to be solubilized and the parameters that influence its solubilization.

Funding information This project was supported by the University of Beira Interior-Health Sciences Research Centre (CICS). Santos FM received a fellowship (CENTRO-07-ST24-FEDER-002014) and a doctoral fellowship (SFRH/BD/112526/2015) from FCT. Gaspar LM received a fellowship from Novartis Farma-Produtos Farmacêuticos, SA. This work is supported by FEDER funds through the POCI - COMPETE 2020 - Operational Programme Competitiveness and Internationalisation in Axis I-Strengthening research, technological development and innovation Project (POCI-01-0145-FEDER-007491) and National Funds by FCT_Foundation for Science and Technology Project (UID/Multi/ 00709/2013). This work was also supported by the Applied Molecular Biosciences Unit- UCIBIO which is financed by national funds from FCT/MCTES (UID/Multi/04378/2019). CNB-CSIC proteomics lab is a member of Proteored, PRB2-ISCIII and is supported by grant PT13/0001, of the PE I +D+i 2013-2016, funded by ISCIII and FEDER.

\section{Compliance with ethical standards}

Conflict of interest The authors declare that they have no conflict of interest.

Research involving human participants and/or animals The protocol for sample collection was approved by the Ethics Committee of LeiriaPombal Hospital, Portugal (Code: CHL-15481). An informed consent from all patients was obtained in agreement with the Declaration of Helsinki.

\section{References}

1. Semba RD, Enghild JJ, Venkatraman V, Dyrlund TF, Van Eyk JE. The Human Eye Proteome Project: perspectives on an emerging proteome. Proteomics. 2013;13:2500-11.

2. Jay NL, Gillies M. Proteomic analysis of ophthalmic disease. Clin Exp Ophthalmol. 2012;40:755-63. https://doi.org/10.1111/j.14429071.2012.02788.x.

3. Rocha AS, Santos FM, Monteiro JP, Castro-de-Sousa JP, Queiroz JA, Tomaz CT, et al. Trends in proteomic analysis of human vitreous humor samples. Electrophoresis. 2014;35:2495-508. https:// doi.org/10.1002/elps.201400049.

4. Monteiro JP, Santos FM, Rocha AS, Castro-de-Sousa JP, Queiroz JA, Passarinha LA, et al. Vitreous humor in the pathologic scope: insights from proteomic approaches. PROTEOMICS Clin Appl. 2015;9:187-202. https://doi.org/10.1002/prca.201400133.

5. Mahajan VB, Skeie JM. Translational vitreous proteomics. Proteomics Clin Appl. 2014;8:204-8. https://doi.org/10.1002/ prca.201300062.

6. Sang JK, Kim S, Park J, Hong KL, Kyong SP, Hyeong GY, et al. Differential expression of vitreous proteins in proliferative diabetic retinopathy. Curr Eye Res. 2006;31:231-40. https://doi.org/10. 1080/02713680600557030.

7. Nakanishi T, Koyama R, Ikeda T, Shimizu A. Catalogue of soluble proteins in the human vitreous humor: comparison between diabetic retinopathy and macular hole. J Chromatogr B Anal Technol Biomed Life Sci. 2002;776:89-100. https://doi.org/10.1016/ S1570-0232(02)00078-8.

8. Koss MJ, Hoffmann J, Nguyen N, Pfister M, Mischak H, Mullen $\mathrm{W}$, et al. Proteomics of vitreous humor of patients with exudative 
age-related macular degeneration. PLoS One. 2014;9:1-11. https:// doi.org/10.1371/journal.pone.0096895.

9. Loukovaara S, Nurkkala H, Tamene F, Gucciardo E, Liu X, Repo P, et al. Quantitative proteomics analysis of vitreous humor from diabetic retinopathy patients. J Proteome Res. 2015;14:5131-43. https://doi.org/10.1021/acs.jproteome.5b00900.

10. Santos FM, Gaspar LM, Ciordia S, Rocha AS, Castro e Sousa J, Paradela A, et al. iTRAQ quantitative proteomic analysis of vitreous from patients with retinal detachment. Int J Mol Sci. 2018;19: 1157. https://doi.org/10.3390/ijms19041157.

11. Öhman T, Tamene F, Göös H, Loukovaara S, Varjosalo M. Systems pathology analysis identifies neurodegenerative nature of agerelated vitreoretinal interface diseases. Aging Cell. 2018;17. https://doi.org/10.1111/acel.12809.

12. Shitama T, Hayashi H, Noge S, Uchio E, Oshima K, Haniu H, et al. Proteome profiling of vitreoretinal diseases by cluster analysis. Proteomics Clin Appl. 2008;2:1265-80. https://doi.org/10.1002/ prca.200800017.

13. Yamane K, Minamoto A, Yamashita H, Takamura H, MiyamotoMyoken Y, Yoshizato K, et al. Proteome analysis of human vitreous proteins. Mol Cell Proteomics. 2003;2:1177-87. https://doi.org/10. 1074/mcp.M300038-MCP200.

14. Kim T, Sang JK, Kim K, Kang UB, Lee C, Kyong SP, et al. Profiling of vitreous proteomes from proliferative diabetic retinopathy and nondiabetic patients. Proteomics. 2007;7:4203-15. https:// doi.org/10.1002/pmic.200700745.

15. Neal RE, Bettelheim FA, Lin C, Winn KC, Garland DL, Zigler JS. Alterations in human vitreous humour following cataract extraction. Exp Eye Res. 2005;80:337-47. https://doi.org/10.1016/j. exer.2004.09.015.

16. Sugioka K, Saito A, Kusaka S, Kuniyoshi K, Shimomura Y. Identification of vitreous proteins in retinopathy of prematurity. Biochem Biophys Res Commun. 2017;488:483-8. https://doi.org/ 10.1016/j.bbrc.2017.05.067.

17. Gao B-B, Chen X, Timothy N, Aiello LP, Feener EP. Characterization of the vitreous proteome in diabetes without diabetic retinopathy and diabetes with proliferative diabetic retinopathy. J Proteome Res. 2008;7:2516-25. https://doi.org/10.1021/ pr800112g.

18. Gaspar LM, Santos FM, Albuquerque T, Castro-de-Sousa JP, Passarinha LA, Tomaz CT. Proteome analysis of vitreous humor in retinal detachment using two different flow-charts for protein fractionation. J Chromatogr B Anal Technol Biomed Life Sci. 2017;1061-1062:334-41. https://doi.org/10.1016/j.jchromb.2017. 07.049 .

19. Reich M, Dacheva I, Siwy J, Mullen W, Schanstra JP, Choi CY, et al. Proteomics of vitreous in neovascular age-related macular degeneration. Exp Eye Res. 2016;146:107-17. https://doi.org/10. 1016/j.exer.2016.01.001.

20. Rogowska-Wrzesinska A, Le Bihan MC, Thaysen-Andersen M, Roepstorff P. 2D gels still have a niche in proteomics. J Proteome. 2013;88:4-13. https://doi.org/10.1016/j.jprot.2013.01.010.

21. Oliveira BM, Coorssen JR, Martins-de-Souza D. 2DE: the phoenix of proteomics. J Proteome. 2014;104:140-50. https://doi.org/10. 1016/j.jprot.2014.03.035.

22. Gauci V, Wright E, Coorssen J. Quantitative proteomics: assessing the spectrum of in-gel protein detection methods. J Chem Biol. 2011;4:3-29. https://doi.org/10.1007/s12154-010-0043-5.

23. Magdeldin S, Enany S, Yoshida Y, Xu B, Zhang Y, Zureena Z, et al. Basics and recent advances of two dimensional- polyacrylamide gel electrophoresis. Clin Proteomics. 2014;11:16. https://doi.org/10. 1186/1559-0275-11-16.

24. Valente KN, Choe LH, Lenhoff AM, Lee KH. Optimization of protein sample preparation for two-dimensional electrophoresis. Electrophoresis. 2012;33:1947-57. https://doi.org/10.1002/elps. 201100659.
25. Chen CPC, Hsu CC, Yeh WL, Lin HC, Hsieh SY, Lin SC, et al. Optimizing human synovial fluid preparation for two-dimensional gel electrophoresis. Proteome Sci. 2011;9. https://doi.org/10.1186/ 1477-5956-9-65.

26. Saraygord-Afshari N, Naderi-Manesh H, Naderi M. Increasing proteome coverage for gel-based human tear proteome maps: towards a more comprehensive profiling. Biomed Chromatogr. 2015;29: 1056-67. https://doi.org/10.1002/bmc.3392.

27. Westermeier R. Looking at proteins from two dimensions: a review on five decades of 2D electrophoresis. Arch Physiol Biochem. 2014;120:168-72. https://doi.org/10.3109/13813455.2014. 945188.

28. López JL. Two-dimensional electrophoresis in proteome expression analysis. J Chromatogr B Anal Technol Biomed Life Sci. 2007;849: 190-202. https://doi.org/10.1016/j.jchromb.2006.11.049.

29. Rabilloud T, Lelong C. Two-dimensional gel electrophoresis in proteomics: a tutorial. J Proteome. 2011;74:1829-41. https://doi. org/10.1016/j.jprot.2011.05.040.

30. Guo C-G, Li S, Wang H-Y, Zhang D, Li G-Q, Zhang J, et al. Study on stability mechanism of immobilized $\mathrm{pH}$ gradient in isoelectric focusing via the Svensson-Tiselius differential equation and moving reaction boundary. Talanta. 2013;111:20-7. https://doi.org/10. 1016/J.TALANTA.2013.03.026.

31. Cao C-X. Moving chemical reaction boundary and isoelectric focusing I. Conditional equations for Svensson-Tiselius' differential equation of solute concentration distribution in idealized isoelectric focusing at steady state. 1998.

32. Slibinskas R, Ražanskas R, Zinkevičiute R, Čiplys E. Comparison of first dimension IPG and NEPHGE techniques in twodimensional gel electrophoresis experiment with cytosolic unfolded protein response in Saccharomyces cerevisiae. Proteome Sci. 2013;11. https://doi.org/10.1186/1477-5956-11-36.

33. Hanneken M, Šlais K, König S. pI-Control in comparative fluorescence gel electrophoresis (CoFGE) using amphoteric azo dyes. EuPA Open Proteomics. 2015;8:36-9. https://doi.org/10.1016/j. euprot.2015.03.003.

34. Guo C-G, Shang Z, Yan J, Li S, Li G-Q, Liu R-Z, et al. A tunable isoelectric focusing via moving reaction boundary for twodimensional gel electrophoresis and proteomics. Talanta. 2015;137:197-203. https://doi.org/10.1016/J.TALANTA.2015.01. 038.

35. Moche M, Albrecht D, Maaß S, Hecker M, Westermeier R, Büttner $\mathrm{K}$. The new horizon in 2D electrophoresis: new technology to increase resolution and sensitivity. Electrophoresis. 2013;34:1510-8. https://doi.org/10.1002/elps.201200618.

36. Hanneken M, König S. Horizontal comparative fluorescence twodimensional gel electrophoresis for improved spot coordinate detection. Electrophoresis. 2014;35:1118-21. https://doi.org/10.1002/ elps.201300507.

37. Khan J, Wei JS, Ringnér M, Saal LH, Ladanyi M, Westermann F, et al. Classification and diagnostic prediction of cancers using gene expression profiling and artificial neural networks. Nat Med. 2001;7:673-9. https://doi.org/10.1038/89044.

38. Lancashire LJ, Lemetre C, Ball GR. An introduction to artificial neural networks in bioinformatics - application to complex microarray and mass spectrometry datasets in cancer studies. Brief Bioinform. 2009;10:315-29. https://doi.org/10.1093/bib/bbp012.

39. Candiano G, Bruschi M, Musante L, Santucci L, Ghiggeri GM, Carnemolla B, et al. Blue silver: a very sensitive colloidal Coomassie G-250 staining for proteome analysis. Electrophoresis. 2004;25:1327-33. https://doi.org/10.1002/elps.200305844.

40. Patel N, Solanki E, Picciani R, Cavett V, Caldwell-Busby JA, Bhattacharya SK. Strategies to recover proteins from ocular tissues for proteomics. Proteomics. 2008;8:1055-70. https://doi.org/10. 1002/pmic. 200700856. 
41. Görg A, Postel W, Friedrich C, Kuick R, Strahler JR, Hanash SM. Temperature-dependent spot positional variability in twodimensional polypeptide patterns. Electrophoresis. 1991;12:6538. https://doi.org/10.1002/elps.1150120910.

42. Nor NM, Mohamed MS, Loh TC, Foo HL, Rahim RA, Tan JS, et al. Comparative analyses on medium optimization using onefactor-at-a-time, response surface methodology, and artificial neural network for lysine-methionine biosynthesis by Pediococcus pentosaceus RF-1. Biotechnol Biotechnol Equip. 2017;31:93547. https://doi.org/10.1080/13102818.2017.1335177.

43. Pedro AQ, Martins LM, Dias JML, Bonifácio MJ, Queiroz JA, Passarinha LA. An artificial neural network for membrane-bound catechol-O-methyltransferase biosynthesis with Pichia pastoris methanol-induced cultures. Microb Cell Factories. 2015;14:113. https://doi.org/10.1186/s12934-015-0304-7.

44. Brown SR, Staff M, Lee R, Love J, Parker DA, Aves SJ, et al. Design of experiments methodology to build a multifactorial statistical model describing the metabolic interactions of alcohol dehydrogenase isozymes in the ethanol biosynthetic pathway of the yeast Saccharomyces cerevisiae. ACS Synth Biol. 2018;7:167684. https://doi.org/10.1021/acssynbio.8b00112.

45. Padula M, Berry I, O’Rourke M, Raymond B, Santos J, Djordjevic SP. A comprehensive guide for performing sample preparation and top-down protein analysis. Proteomes. 2017;5:11. https://doi.org/ 10.3390/proteomes5020011.

46. Görg A, Boguth G, Obermaier C, Posch A, Weiss W. Twodimensional polyacrylamide gel electrophoresis with immobilized $\mathrm{pH}$ gradients in the first dimension (IPG-Dalt): the state of the art and the controversy of vertical versus horizontal systems. Electrophoresis. 1995;16:1079-86.

Publisher's note Springer Nature remains neutral with regard to jurisdictional claims in published maps and institutional affiliations. 